\title{
On the role of the seawater absorption-to-attenuation ratio in the radiance polarization above the southern Baltic surface
}

\author{
Włodzimierz Freda ${ }^{1}$, Kamila Haule ${ }^{1}$, and Sławomir Sagan ${ }^{2}$ \\ ${ }^{1}$ Department of Physics, Gdynia Maritime University, Gdynia, 81-225, Poland \\ ${ }^{2}$ Institute of Oceanology, Polish Academy of Sciences, Sopot, 81-712, Poland \\ Correspondence: Włodzimierz Freda (wfreda@am.gdynia.pl)
}

Received: 31 October 2018 - Discussion started: 28 November 2018

Revised: 29 April 2019 - Accepted: 2 May 2019 - Published: 17 June 2019

\begin{abstract}
Information about polarization of light leaving the ocean surface has the potential to improve the quality of biooptical parameter retrieval from ocean color remote sensing (OCRS). This improvement can be applied in numerous ways, such as limiting of Sun glints and obtaining information about atmospheric aerosol properties for atmospheric correction as well as increasing the accuracy of the algorithms based on the water-leaving signal. Polarization signals at the top of the atmosphere (ToA) that include the waterleaving signal are strongly influenced by atmospheric molecular scattering and by direct Sun and sky reflections from the sea surface. For these reasons, it is necessary to better understand the factors that change the polarization of light in the atmosphere-ocean system, especially in coastal zones affected by dynamic changes. In this paper, the influence of seasonal variability of light absorption and scattering coefficients (inherent optical properties; IOPs) of seawater, wind speed and solar zenith angle (SZA) on the polarization of upwelling radiance over the sea surface in the visible light bands is discussed. The results come from a polarized radiative transfer model based on the Monte Carlo code and applied to the atmosphere-ocean system using averaged IOPs as input data. The results, presented in the form of polar plots of the total upwelling radiance degree of polarization (DoP), indicate that regardless of the wavelength of light and type of water, the highest value of the above-water DoP is strongly correlated with the absorption-to-attenuation ratio. The correlation is a power function that depends on both the SZA and the wind speed. The correlation versatility for different wavelengths of light is very unusual in optics of the sea and is therefore worth emphasizing.
\end{abstract}

\section{Introduction}

Satellite ocean color radiometry has been developed for decades to study the interaction of a light field within the visible part of the spectrum (i.e., 400-700 nm) with the different optically significant constituents of seawater. The research has been focusing on information coming from the intensity of water-leaving light - its measurement, retrieval, correlations and interpretation (e.g., Volpe et al., 2012; Zibordi et al., 2013; Sammartino et al., 2015). However, in addition to the light intensity, consideration of light polarization has been demonstrated to improve the accuracy of the information from a variety of remote sensing applications, i.e., in remote radar measurements (Hajnsek et al., 2003; Soloviev et al., 2012; Benassai et al., 2013) and in atmospheric correction algorithms (Chowdhary et al., 2002).

Vector radiative transfer simulations have shown that the polarization of the underwater light field is sensitive to the nature of the suspended marine particles. Ibrahim et al. (2012) and Ibrahim et al. (2016) demonstrated that the attenuation-to-absorption ratio influences the polarization of upwelling radiance below the sea surface. Polarized measurements have also been performed near and above the sea surface. Reduction of Sun glints to improve the ocean color retrieval has been studied by He et al. (2014), Zhou et al. (2017) or Shaw and Vollmer (2017), and limitation of sky reflections by observation of sea surface at the Brewster angle from the shipboard has been examined by Wood and Cunningham (2001) and Cunningham et al. (2002). Polarization distribution of skylight reflected off the rough sea surface has been recently examined in many independent studies, e.g., by Zhou et al. (2013), Harmel et al. (2012), Mobley (2015), Hieronymi (2016), Foster and Gilerson (2016) 
and D'Alimonte and Kajiyama (2016). Zhou et al. (2013) simulated the degree of polarization as well as the angle of polarization (AoP) for reflected parts of upwelling radiance and discussed its variability with solar zenith angle (SZA) for 0, 30, 60 and $90^{\circ}$. Moreover, Zhou et al. (2013) showed the influence of wind speed and direction on the polarization pattern of reflected radiance. Harmel et al. (2012) showed that knowledge of the polarization field of the diffuse skylight significantly improves above-water radiometry estimates, in particular in the blue part of the spectrum where the reflected skylight is dominant. Mobley (2015) and Hieronymi (2016) applied polarized radiative transfer in order to show the role of sky polarization in the retrieval of radiance and irradiance reflectance of the windblown sea surface. Likewise, D'Alimonte and Kajiyama (2016) discussed joint effect of polarization and the sea-surface statistics on the in situ waterleaving radiance. Foster and Gilerson (2016) provided transfer functions for surface-reflected polarized skylight and upward transmission of light through the sea surface and estimated the sensitivity of polarized components to environmental conditions. Furthermore, polarized radiative transfer simulations have shown the effect of marine suspensions on the polarization of light recorded above the sea surface (see Chami, 2007; Chami et al., 2015). Further studies have also shown the possibility of knowing the composition of the suspension, i.e., the ratio of mineral to organic suspension, using polarization properties of water-leaving radiance (see Gilerson et al., 2006; Chami, 2007; Tonizzo et al., 2011). The intent of the authors was to show the seasonal variability of polarization of the upwelling radiance above the sea surface.

The most challenging part in the analysis of the signal registered by passive radiometric sensors at the top of the atmosphere is to remove the contribution of the reflected photons at the air-sea interface as well as the contribution of the atmosphere. To assess the water-leaving radiance, $L_{\mathrm{w}}(\lambda)$, on the level of accuracy required to derive accurate estimates of the desired water components, other characteristics and methods that support the advanced atmospheric correction and parameter retrieval have been searched, i.e., the black pixel assumption (Siegel et al., 2000), using near-infrared and shortwave infrared bands (Wang et al., 2007), using unpolarized top of the atmosphere (ToA) reflectance (Frouin et al., 1994), or using polarized water-leaving radiance (Zhai et al. 2017). The latter showed that, in general, the polarized signal at the ToA is $2-3$ times higher than its waterleaving part because of the influence of molecular scattering in the atmosphere. Discussions on the use of remote polarization measurements to determine the aerosol properties that can then be used for atmospheric correction are included in Chowdhary et al. (2002), Mishchenko and Travis (1997) and Hasekamp and Landgraf (2005). Harmel and Chami (2013) demonstrated that polarization-based atmospheric correction improves the retrieval of the aerosol properties over open ocean waters. Pust et al. (2011) showed that measurements of the degree of polarization of the sky (made from the ground) can also be helpful in obtaining aerosol parameters. He et al. (2014) proposed to measure the parallel polarization radiance (PPR) instead of radiance intensity at ToA. According to them, such measurements would enhance the ocean color remote sensing (OCRS) capability. Liu et al. (2017), based on radiative transfer modeling and laboratory measurement, showed that the concentration of particulate matter influences the PPR measured at ToA.

Polarized signal can be measured from the satellite sensors, e.g., POLarization and Directionality of the Earth's Reflectances sensor (POLDER-2), above water using a polarization imaging camera (Freda et al., 2015) or underwater as by Loisel et al. (2008) and Harmel et al. (2011). The measurements are often supported by numerical modeling. Although there are many ongoing numerical radiative transfer models applied to ocean-atmosphere system, only some of them include light polarization (e.g., Schulz et al., 1999; Ota et al., 2010; Piskozub and Freda, 2013; Chami et al., 2015, Korkin et al., 2017). Kokhanovsky (2010) compared several vector radiative transfer models.

The polarized radiative transfer has been applied for the open ocean-atmospheric system since the 1970s (see, for example, Kattawar et al., 1973); however, its significance in coastal zone remote sensing has been highlighted in the last decade. Chami et al. (2015) applied the polarized radiative transfer to retrieve the polarizing properties of the marine phytoplankton and minerals for different water conditions. Their analysis revealed that the application of the polarization of light in ocean color algorithms might significantly improve the retrieval of hydrosol properties, especially in coastal waters. Piskozub and Freda (2013) applied their polarized radiative transfer model to the Baltic Sea. They examined how scattering properties of seawater represented by a single scattering albedo affected the polarization of waterleaving radiance. They demonstrated the impact of air bubble layers of various concentrations on the degree of polarization of water-leaving light. They also concluded that polarization remote sensing should be performed on a plane tilted approximately $90^{\circ}$ from the solar azimuth angle to avoid Sun glints. The involvement of polarization in radiative transfer analysis seems to be especially important in coastal areas, knowing that they undergo dynamic changes due to human proximity (Drozdowska et al., 2017), river inflows and the occurrence of pollution, including optically significant oil pollution (Drozdowska et al., 2013). There has been several significant studies performed in coastal zones of New York Harbor (Tonizzo et al., 2009), Long Island Sound (Harmel et al., 2012) or a selected few places from the East Coast and Gulf of Mexico (Tonizzo et al., 2011). Nevertheless, little attention has been paid to the measurement and modeling of light polarization in some coastal areas and closed water basins like the Baltic Sea characterized by optically complex waters. The Baltic Sea represents a region of a great economic importance, extremely high marine traffic and the impact of inflows from nine different surrounding countries. Inherent 
optical properties of Baltic seawater and its constituents have been in the spotlight for oceanographers for two decades. In addition to regular measurements of depth profiles of absorption and attenuation coefficients, measurements for different components of seawater have been performed. Colored dissolved organic matter (CDOM) is known to be the primary absorber in the Baltic Sea (Kowalczuk et al., 2006, 2010), and its impact on the total absorption coefficient for blue light can reach up to $80 \%$ (Kowalczuk et al., 2005). Kowalczuk (1999) and Kowalczuk and Kaczmarek (1996) found that the high absorption of CDOM in spring and low absorption in winter is due to the biological cycle as well as the seasonal variability of the inlet with river water and its mixing. The aim for a better correlation of the spectral remote sensing reflectance $R_{\mathrm{rs}}$ ratio with the absorption coefficient of CDOM has been intensively researched within the SatBaltic system (Meler et al., 2016a). Measurements of suspended matter inherent optical properties (IOPs) in the Baltic, i.e., particle absorption and particle scattering coefficients, have been compared with biogeochemical characteristics of suspended matter such as concentrations of suspended particulate matter, particulate organic matter, particulate organic carbon and chlorophyll $a$ (Woźniak et al., 2011). Meler et al. (2016b) concluded that absorption properties of non-algal particles undergo larger regional than seasonal variability. In addition to the absorption and attenuation coefficients, the volume scattering functions (VSFs) were also measured in the waters of the southern Baltic (Freda et al., 2007; Freda and Piskozub, 2007; Freda, 2012). Unique measurements have been performed by the prototype volume scattering meter, characterized by an angular resolution of $0.3^{\circ}$ and a range of scattering angles from 0.6 to $177.9^{\circ}$, described by Lee and Lewis (2003). The same instrument has also been used by Chami et al. (2005) in the Black Sea and by Berthon et al. (2007) in the Adriatic Sea. Baltic Sea waters are often affected by small-scale oil pollution (Rudź et al., 2013). The influence of dispersed oil droplets on the absorption coefficient of seawater was researched by Otremba (2007) as well as Haule and Freda (2016), while their influence on scattering properties has been tested by Freda (2014). The consequences of changes in IOPs for remote detection of dispersed oil pollution have been discussed by Otremba et al. (2013), Otremba (2016) and Haule et al. (2017) based on radiative transfer modeling. Knowledge and datasets collected in the Baltic throughout the past two decades helped us to perform a unique study on polarized radiation above the southern Baltic sea surface. This study shows the application of a polarized radiative transfer model in three optically different regions, two seasons and two different sea states. The study highlights the possibilities and consequences of including polarization information in bio-optical models of seawater.

\section{Methods}

The difficulty of comparison of upwelling radiance degree of polarization (DoP) over a wind-roughened southern Baltic surface for various seasons is caused by the small number of sunny days in winter and too many variable weather factors that would make it difficult to explain the differences. These undesirable weather factors are different aerosol optical depths, sky overcast and changing speed and direction of wind relative to the position of the Sun. For those reasons, we applied a polarized radiative transfer model based on the Monte Carlo code to describe the effect of seasonal changes on the polarization of upwelling radiance. The simulations involved seasonally averaged measurements of inherent optical properties from the southern Baltic basin and were run for constant weather conditions. For a detailed description of the inputs and conditions under which the simulation is performed, see the following subsections.

\subsection{Polarized radiative transfer model - theoretical background}

Numerical simulations were carried out using the Monte Carlo algorithm created by Jacek Piskozub and applied previously in Piskozub and Freda (2013). The algorithm solves the vector radiative transfer equation for the atmosphere-ocean system using the successive orders of scattering method and the Stokes formalism to track the polarization of photons. The algorithm collects information about virtual photons involved statistically in optical processes: reflection at the rough sea surface, refraction at the air-water interface, scattering and absorption within the water body and reaching the ToA. Moreover, the original Monte Carlo algorithm has been modified to track polarization changes of each photon during these processes. The unmodified version of the algorithm was successfully used, with results published in Piskozub et al. (2001), Stramski and Piskozub (2003), McKee et al. $(2008,2013)$ or Piskozub and McKee (2011).

Polarization information is described by four elements of the Stokes vector: $S=[I, Q, U, V]^{T}$, where $I$ is the total radiance of light, $Q$ describes the radiance of linearly polarized light (vertical to horizontal), $U$ describes the radiance of linearly polarized light (diagonal right skewed to left skewed), $V$ describes the circular polarization (clockwise to counterclockwise), and $T$ denotes the transposition. Three elements $(Q, U$ and $V)$ of the Stokes vector may be both positive or negative. The single quantity that characterizes these properties is the degree of polarization:

$\mathrm{DoP}=\frac{\sqrt{Q^{2}+U^{2}+V^{2}}}{I}$.

The defined degree of polarization is often replaced by the degree of linear polarization (DoLP).

$\operatorname{DoLP}=\frac{\sqrt{Q^{2}+U^{2}}}{I}$ 
The latter hardly differs from DoP because circular polarization is relatively rare in nature (Cronin and Marshall, 2011). The circular polarization represented by the $V$ element of the Stokes vector does not appear in seawater as a result of scattering; see off-diagonal Mueller matrix elements in Voss and Fry (1984). It is measurable in light internally reflected from the underside of the sea's surface (Ivanoff and Watermann, 1958).

Our polarized radiative transfer model involves a virtual light source to send randomly polarized photons and track their pathways in the means of the probability of occurrence of the processes mentioned above. Reflection and refraction processes are described by Fresnel equations, and the slopes of the sea surface are characterized by the wind-dependent distribution of Cox and Munk (1956). The algorithm does not take into account additional depolarization due to enhanced whitecap fraction, described by Hu et al. (2008) - that is likely for high wind speed. The probability of processes within the water body is determined by the corresponding coefficients of absorption and scattering (including multiple scattering). Angular distribution of scattered photons is described by phase functions that, for both atmosphere and sea depth, are characterized separately for molecular scattering and particle scattering. Polarization properties of particle scattering are described by Mueller matrices that for seawater are taken from Voss and Fry (1984) and for atmospheric aerosol particles from Volten et al. (2001). The model outputs the angular distribution of the upwelling radiance and its degree of polarization at any desired level, which are presented in form of polar plots. Some of the results are additionally specified in the principal plane.

\subsection{Polarized radiative transfer model - input parameters}

This section reports the input parameters used in the computations. The dataset of the absorption and attenuation coefficients of seawater constituents come from in situ measurements in the southern Baltic contained in Sagan (2008). It is the largest dataset of ac-9 (WET Labs, Inc.) measurements in the southern Baltic that was published in a tabular form of average values, extreme values and standard deviations. The instrument was calibrated in ultrapure water and routinely checked for stability with air readings. The standard recommended data processing was performed (Zaneveld et al., 1994). Absolute precision of measurement is $0.005 \mathrm{~m}^{-1}$, while relative precision is estimated from $4 \%$ in clear waters to $12 \%$ in the areas of turbid waters. The data have been recorded during cyclical cruises aboard R/V Oceania in 1999 and 2003 to 2005 . Measurements were made in different months of the year. The dataset was divided into two seasons, here called "winter", for the months from November to March, and "summer", for the months from April to October. The summer season is characterized by strong phytoplankton growth and the winter season by low biological ac- tivity. In addition, Sagan (2008) distinguished three regions: open Baltic, gulfs (Gulf of Gdańsk and Pomeranian Gulf) and coastal waters. The measuring stations, divided into these three types of water, are shown in Fig. 1. For defined regions - open Baltic and coastal areas - those two datasets are statistically significantly different for all optical parameters $(t$ test for means) at the level $p<0.05$ by Sagan (2008).

Total absorption coefficient taken to the simulation is a sum $a_{\mathrm{t}}=a_{\mathrm{pg}}+a_{\mathrm{w}}$, where $a_{\mathrm{pg}}$ is an average absorption coefficient (particle and dissolved fraction) of the $N$ number of measured depth profiles (see Table 1) made with the ac-9 after Sagan (2008), and $a_{\mathrm{w}}$ is the pure water absorption coefficient and comes from Pope and Fry (1997). Similarly, the total attenuation coefficient is defined as $c_{\mathrm{t}}=c_{\mathrm{pg}}+a_{\mathrm{w}}+b_{\mathrm{w}}$, where the component $c_{\text {pg }}$ comes directly from Sagan (2008), but to get the total attenuation coefficient, it was enlarged by clean water components of absorption $a_{\mathrm{w}}$ and scattering $b_{\mathrm{w}}$ (Smith and Baker, 1981). According to Sagan (2008), the highest values of IOPs and their highest variability are observed for the water of gulfs and estuaries of rivers that are located nearby. The simulations are carried out at nine wavelengths, namely, 412, 440, 488, 510, 532, 555, 650, 676 and $715 \mathrm{~nm}$, which correspond to the ac- 9 and are commonly dedicated to ocean color analysis.

Solar zenith angles in the southern Baltic region depend strongly on the season. In months described by Sagan (2008) as the summer season, the highest Sun position over the horizon, which means the minimum of SZA during Sun culmination, varies between $31^{\circ}$ in June (the longest day of the year) and $69^{\circ}$ at the end of October. In the modeling, a single value of $45^{\circ}$ was chosen as a summer SZA. For months of the winter season, the minimum of SZA varies between $50^{\circ}$ in the end of March and $78^{\circ}$ in December (the shortest day). Given values are reached at approximately noon and are higher in the rest of the days. That is why SZA of $75^{\circ}$ is chosen as a representative for the winter season. Computations are performed for the direction of wind twisted by $45^{\circ}$ from the Sun reflection plane, chosen arbitrarily. Two wind speeds of 5 and $15 \mathrm{~m} \mathrm{~s}^{-1}$ are considered. Aerosol optical thickness of 0.12 , independent of the wavelength and the same for both seasons, was applied to all simulations. This allowed us to observe DoP variations and correlations that were not affected by aerosol changes.

Here and in the following figures, the celestial hemisphere and its reflection patterns are represented in a twodimensional coordinate system. The zenith and the nadir are at the origin and the horizon is represented by the outermost circle. The zenith angle and azimuth angle are measured radially and tangentially, respectively. The solar azimuth angle is always set to 0 . 


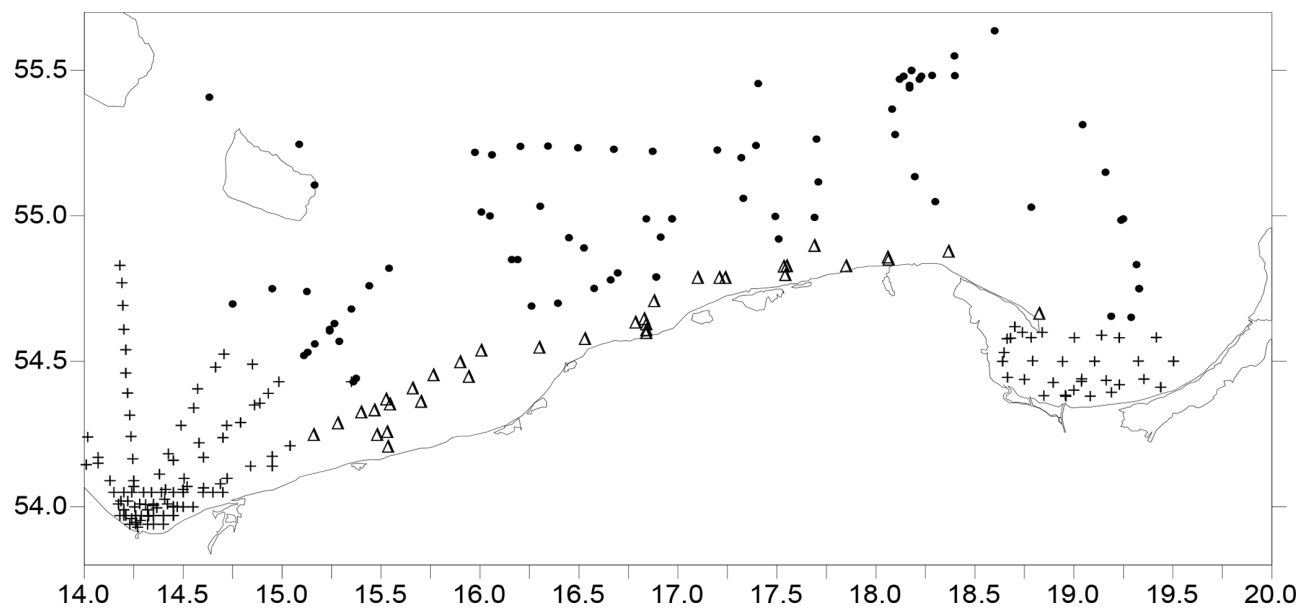

Figure 1. The area of the southern Baltic Sea, on which the positions of measurement stations are marked, divided into three areas: Pomeranian Gulf and Gulf of Gdańsk $(+)$, coastal water $(\Delta)$ and open Baltic water $(\bullet)$.

Table 1. Average values of total absorption coefficients, total attenuation coefficients, their standard deviations and their ratios. All values measured by Sagan (2008) in southern Baltic in 1999 and 2003 to 2005 are averaged for depths 0 to $5 \mathrm{~m}$ and then averaged for $N$ measuring stations.

\begin{tabular}{|c|c|c|c|c|c|c|c|c|c|c|c|c|c|c|c|}
\hline \multicolumn{16}{|c|}{ Summer season } \\
\hline \multirow[b]{2}{*}{$\lambda(\mathrm{nm})$} & \multicolumn{5}{|c|}{ Baltic, $N=930$} & \multicolumn{5}{|c|}{ Gulfs, $N=1428$} & \multicolumn{5}{|c|}{ Coastal waters, $N=132$} \\
\hline & $a(\lambda)$ & $\sigma_{a}$ & $c(\lambda)$ & $\sigma_{c}$ & $\frac{a(\lambda)}{c(\lambda)}$ & $a(\lambda)$ & $\sigma_{a}$ & $c(\lambda)$ & $\sigma_{c}$ & $\frac{a(\lambda)}{c(\lambda)}$ & $a(\lambda)$ & $\sigma_{a}$ & $c(\lambda)$ & $\sigma_{c}$ & $\frac{a(\lambda)}{c(\lambda)}$ \\
\hline 412 & 0.595 & 0.12 & 1.230 & 0.40 & 0.483 & 1.095 & 0.65 & 2.560 & 1.64 & 0.428 & 0.615 & 0.12 & 1.470 & 0.52 & 0.418 \\
\hline 440 & 0.396 & 0.10 & 0.999 & 0.37 & 0.396 & 0.786 & 0.52 & 2.209 & 1.48 & 0.356 & 0.416 & 0.10 & 1.249 & 0.52 & 0.333 \\
\hline 488 & 0.214 & 0.07 & 0.817 & 0.34 & 0.262 & 0.444 & 0.32 & 1.887 & 1.35 & 0.236 & 0.214 & 0.06 & 1.027 & 0.46 & 0.209 \\
\hline 510 & 0.183 & 0.05 & 0.785 & 0.33 & 0.233 & 0.353 & 0.23 & 1.825 & 1.31 & 0.193 & 0.173 & 0.04 & 0.995 & 0.46 & 0.173 \\
\hline 532 & 0.155 & 0.04 & 0.756 & 0.32 & 0.205 & 0.285 & 0.18 & 1.756 & 1.28 & 0.162 & 0.155 & 0.03 & 0.946 & 0.44 & 0.163 \\
\hline 555 & 0.140 & 0.03 & 0.731 & 0.31 & 0.192 & 0.240 & 0.13 & 1.711 & 1.26 & 0.140 & 0.140 & 0.03 & 0.911 & 0.42 & 0.153 \\
\hline 650 & 0.380 & 0.02 & 0.921 & 0.29 & 0.413 & 0.430 & 0.08 & 1.811 & 1.20 & 0.237 & 0.380 & 0.02 & 1.071 & 0.38 & 0.355 \\
\hline 676 & 0.518 & 0.05 & 1.029 & 0.28 & 0.503 & 0.638 & 0.19 & 1.909 & 1.18 & 0.334 & 0.508 & 0.03 & 1.169 & 0.38 & 0.435 \\
\hline \multicolumn{16}{|c|}{ Winter season } \\
\hline & \multicolumn{5}{|c|}{ Baltic, $N=234$} & \multicolumn{5}{|c|}{ Gulfs, $N=540$} & \multicolumn{5}{|c|}{ Coastal waters, $N=36$} \\
\hline$\lambda(\mathrm{nm})$ & $a(\lambda)$ & $\sigma_{a}$ & $c(\lambda)$ & $\sigma_{c}$ & $\frac{a(\lambda)}{c(\lambda)}$ & $a(\lambda)$ & $\sigma_{a}$ & $c(\lambda)$ & $\sigma_{c}$ & $\frac{a(\lambda)}{c(\lambda)}$ & $a(\lambda)$ & $\sigma_{a}$ & $c(\lambda)$ & $\sigma_{c}$ & $\frac{a(\lambda)}{c(\lambda)}$ \\
\hline 412 & 0.485 & 0.03 & 0.680 & 0.015 & 0.713 & 0.755 & 0.31 & 1.760 & 1.04 & 0.429 & 0.585 & 0.14 & 1.250 & 0.68 & 0.468 \\
\hline 440 & 0.296 & 0.02 & 0.479 & 0.015 & 0.618 & 0.496 & 0.22 & 1.469 & 0.95 & 0.338 & 0.376 & 0.10 & 1.009 & 0.63 & 0.373 \\
\hline 488 & 0.154 & 0.02 & 0.337 & 0.015 & 0.459 & 0.264 & 0.13 & 1.217 & 0.86 & 0.217 & 0.194 & 0.06 & 0.817 & 0.57 & 0.238 \\
\hline 510 & 0.133 & 0.02 & 0.315 & 0.014 & 0.421 & 0.213 & 0.10 & 1.165 & 0.83 & 0.182 & 0.163 & 0.05 & 0.785 & 0.55 & 0.207 \\
\hline 532 & 0.125 & 0.02 & 0.296 & 0.013 & 0.421 & 0.185 & 0.08 & 1.106 & 0.81 & 0.167 & 0.145 & 0.04 & 0.756 & 0.54 & 0.191 \\
\hline 555 & 0.120 & 0.01 & 0.291 & 0.013 & 0.411 & 0.170 & 0.06 & 1.071 & 0.79 & 0.158 & 0.140 & 0.03 & 0.731 & 0.52 & 0.191 \\
\hline 650 & 0.370 & 0.01 & 0.521 & 0.012 & 0.711 & 0.400 & 0.04 & 1.211 & 0.73 & 0.330 & 0.370 & 0.01 & 0.931 & 0.46 & 0.398 \\
\hline 676 & 0.478 & 0.02 & 0.629 & 0.012 & 0.760 & 0.528 & 0.08 & 1.299 & 0.72 & 0.407 & 0.488 & 0.02 & 1.039 & 0.45 & 0.470 \\
\hline
\end{tabular}

\section{Results and discussion}

\subsection{Extreme values of the degree of polarization}

The full set of simulation results is available in the repository Freda (2019). It contains tables of Stokes vector elements for sectors marked with zenith-azimuth coordinates, which allows one to calculate the DoP. Examples of simulation results are presented in Fig. $2 \mathrm{a}$ and $\mathrm{b}$ in the form of polar plots of the degree of polarization of upwelling radiance just above the sea surface. Figure 2a shows the DoP for the average IOPs measured in the open waters of the Baltic Sea for a wave- 
length of $412 \mathrm{~nm}$ in the summer season, while Fig. $2 \mathrm{~b}$ depicts an analogous case for the winter season. These two plots are characterized by one of the highest values of the peak of DoP of 0.88 for summer and 0.84 for winter. The azimuth position of the Sun is $0^{\circ}$ in all cases. Corresponding values of computed upwelling radiance $I$ (in units of $\mathrm{Wm}^{-2} \mathrm{sr}^{-1} \mathrm{~nm}^{-1}$ ) are shown on the plots of Fig. 2c and d on the logarithmic scale (due to their high angular variability).

The small SZA of the summer season $\left(45^{\circ}\right)$ resulted in low values of upwelling radiance that are stretched from the direct reflection point to the horizon, where it is extended both left and right from the azimuth of $180^{\circ}$. The high SZA of the winter season $\left(75^{\circ}\right.$ ) resulted in much higher values of reflected light, which are also stretched from reflection point to the horizon.

Examples of the lowest values of the maximum DoP, referred to as $\max (\mathrm{DoP})$, are shown in Fig. 3a and b. They were obtained for the regions of Gulf of Gdańsk and Pomeranian Gulf, simulated for the spectral band of $555 \mathrm{~nm}$, for the summer season (Fig. 3a) and for the winter season (Fig. 3b).

The maximum values of DoP presented in Fig. 2a (summer season, open Baltic waters) are visible for azimuth angles close to $180^{\circ}$ (direction of reflected Sun) and a zenith angle of approximately $55^{\circ}$ although the solar zenith angle is $45^{\circ}$, while the $\max (\mathrm{DoP})$ in Fig. 3a (summer season, waters of gulfs) is visible for a zenith angle of approximately $60^{\circ}$. In contrast to the summer season case, the maximum DoPs in the winter season are close to the zenith angle of $48^{\circ}$ (Fig. 2b) and $54^{\circ}$ (Fig. 3b), while SZA is $75^{\circ}$. The lower position of the Sun results in a higher position of the maximum DoP of upwelling radiation than its reflection angle, and a higher position of the Sun results in a lower position of the maximum DoP. Another interesting effect is the higher DoP observed for directions close to the incident rays of the Sun (azimuth of $0^{\circ}$ ). In general, in the winter season, the values of DoP are higher than in summer, and zenith angles of this effect are lower in the winter than in the summer season.

\subsection{Spectral variability of the degree of polarization}

The results of Monte Carlo simulations of angular characteristics of DoP of upwelling radiance are presented in Fig. 4. These results are obtained for average IOPs of open Baltic waters for wind speed of $5 \mathrm{~m} \mathrm{~s}^{-1}$ for three wavelengths (440, $555,650 \mathrm{~nm}$ ) and for both seasons. Vertical cross-sections of such polar plots for the same type of water (open Baltic Sea) but additionally for all examined wavelengths and for two speeds of wind, 5 and $15 \mathrm{~m} \mathrm{~s}^{-1}$, are presented in Fig. 5. Such cross-sections show the DoP in the principal plane, including the direction of incident Sun beam (on the left side of the plot), zenith and direction of Sun reflection beam for calm sea surface (on the right side). The azimuth direction of the Sun position, described as $0^{\circ}$ in the polar plots, is marked by negative zenith angles in Fig. 5, while azimuth directions of $180^{\circ}$ that include the Sun reflection beam are marked by positive zenith angles.

The analysis of individual spectral bands shows that high values of DoP correspond to the high absorption-toattenuation ratio for the total of visible light domain (see Table 1). High values of absorption coefficient for $650-676 \mathrm{~nm}$ wavelengths (in the red spectral region) are caused by pure water (see Pope and Fry, 1997), while high absorption coefficients for wavelengths of the blue-green range are caused mainly by CDOM (Kowalczuk et al., 2005). The lowest values of $\max (\mathrm{DoP})$ for each type of water and for each season are observed for the $555 \mathrm{~nm}$ spectral band. The lowest values of absorption and weak spectral variability of the scattering coefficient imply that the wavelength of $555 \mathrm{~nm}$ is characterized by the lowest absorption-to-attenuation ratios due to the existence of a minimum of absorption for seawater containing phytoplankton. Algae cells, depending on the composition of their pigments, may have a minimum of absorption in a wide range of spectral bands from $550 \mathrm{~nm}$ to $660 \mathrm{~nm}$ (Bricaud et al., 2004). Considering the absorption of pure water that is increasing with wavelength (Pope and Fry, 1997), the minimum of the absorption in Baltic waters for the spectral band of $555 \mathrm{~nm}$ results.

The spectral shape of the DoP cross-sections contains two maxima, and their angular positions depend on the absorption-to-attenuation ratio, the season and the wind speed. The angular position of the higher maximum depends mostly on the season, varying from approximately $60^{\circ}$ in the summer to $35-50^{\circ}$ in the winter (see Fig. 5). The lower maximum is observed at the zenith angles between -70 and $-90^{\circ}$ in the summer as well as between -55 and $-70^{\circ}$ in the winter. Higher wind speed of $15 \mathrm{~m} \mathrm{~s}^{-1}$, in comparison to $5 \mathrm{~m} \mathrm{~s}^{-1}$, causes the irregular shape of peaks. Moreover, the higher wind speed causes an increase of the DoP value for a lower maximum in the 650 and $676 \mathrm{~nm}$ spectral bands and its shift to a higher position (toward the zenith). At the same time, the DoP values for shorter wavelength bands are decreased and shifted to a lower position (toward horizon).

\subsection{Regional variability of the degree of polarization}

Computations of DoP were carried out in three optically different regions of the southern Baltic. Such a division is justified in previous studies of optical and hydrological properties of the south Baltic waters (Olszewski et al., 1992). They showed a relationship between the measured values of IOPs and their location in relation to river estuaries, distance from the shore or bathymetry of the bottom.

Comparison of water type influence on the DoP is shown in Fig. 6 for two wavelengths: 440 (Fig. 6a) and $555 \mathrm{~nm}$ (Fig. 6b). The type of water has less influence on the DoP than the season and its representative SZA.

However, the highest values of DoP for most zenith angles and the highest values of its peak $\max (\mathrm{DoP})$ for each season are observed for open Baltic Sea water. Coastal waters 

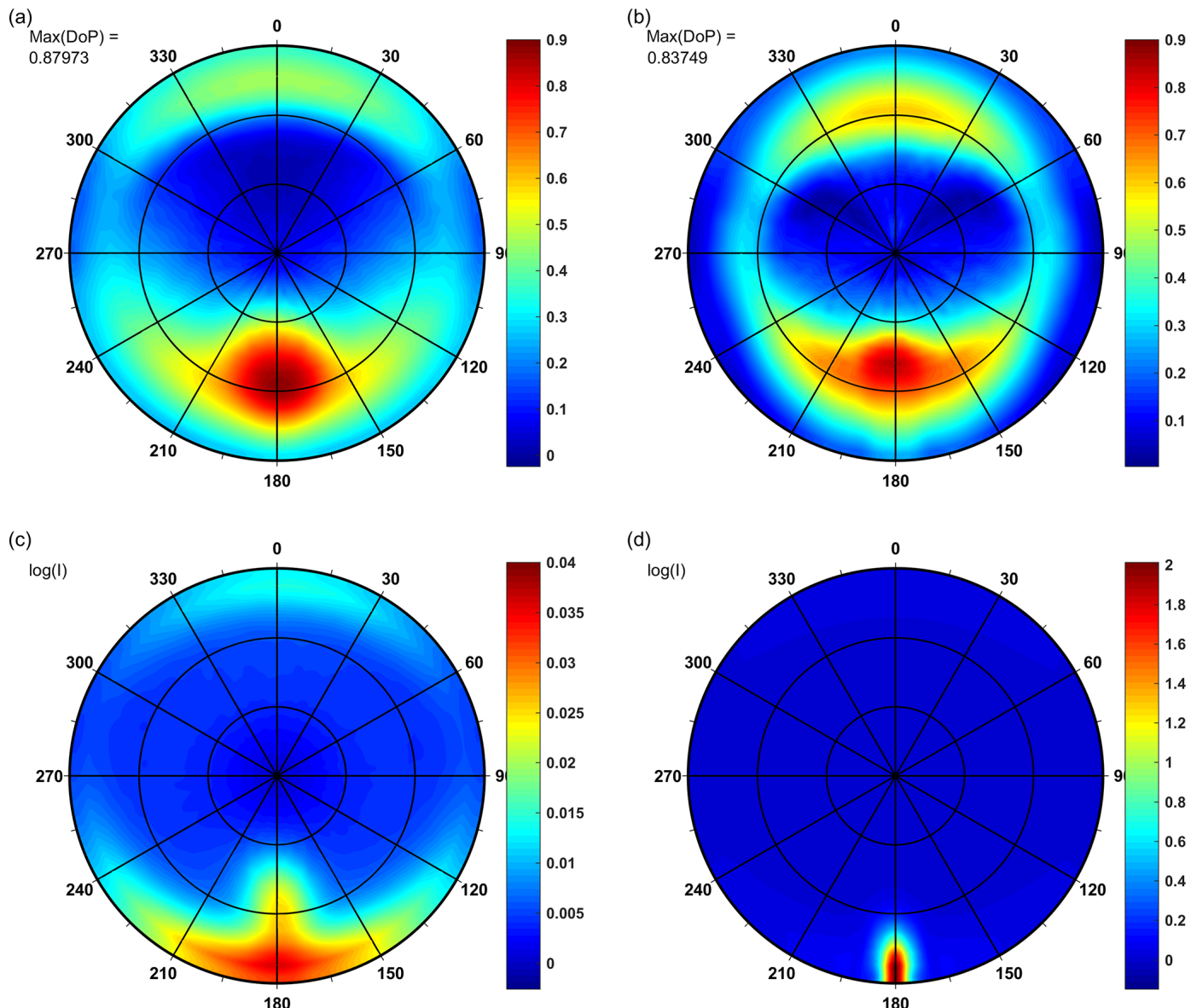

Figure 2. Simulation results of above-water upwelling radiance for average IOPs of open waters of the southern Baltic, wavelength $412 \mathrm{~nm}$, for wind speed of $5 \mathrm{~m} \mathrm{~s}^{-1}$ : (a) DoP in the summer season, SZA $45^{\circ}$, (b) DoP in the winter season, SZA $75^{\circ}$, (c) decimal logarithm of upwelling radiance in the summer season, $\mathrm{SZA} 45^{\circ}$, (d) decimal logarithm of upwelling radiance in the winter season, SZA $75^{\circ}$. Concentric circles inside mean zenith angles of 30 and $60^{\circ}$, respectively.
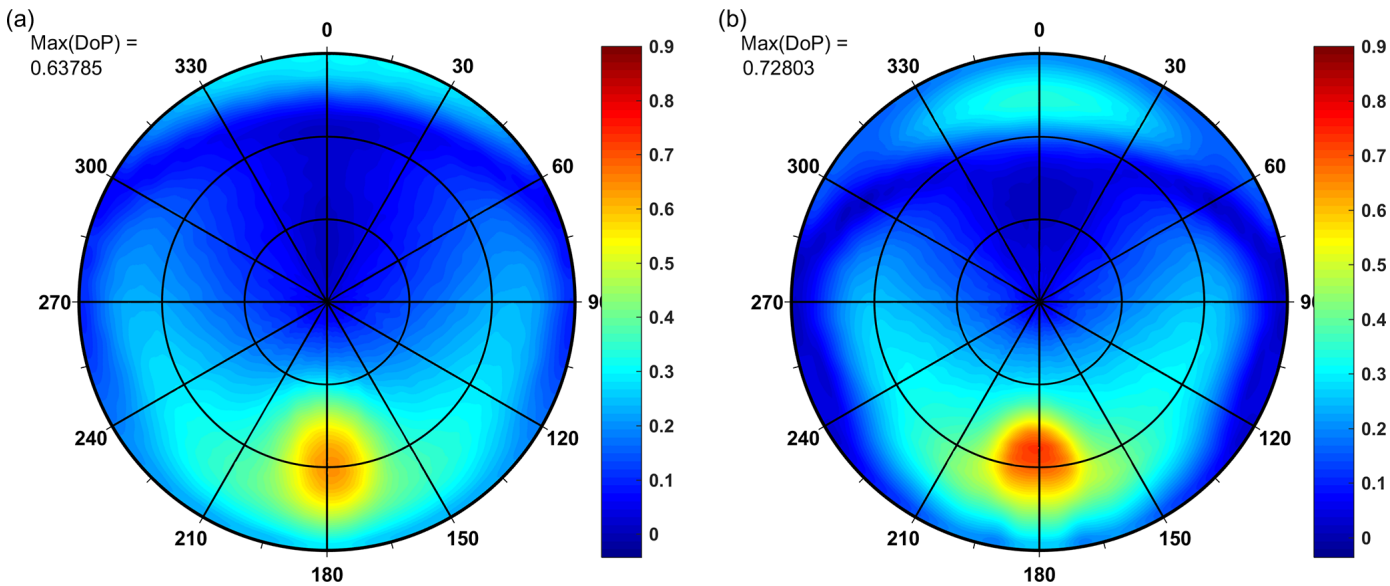

Figure 3. Simulation results of above-water upwelling radiance for average IOPs of gulf waters of the southern Baltic, wavelength $555 \mathrm{~nm}$, for speed of wind of $5 \mathrm{~m} \mathrm{~s}^{-1}$ : (a) DoP in the summer season, SZA $45^{\circ}$, (b) DoP in the winter season, SZA $75^{\circ}$. Concentric circles inside mean zenith angles of 30 and $60^{\circ}$, respectively. 

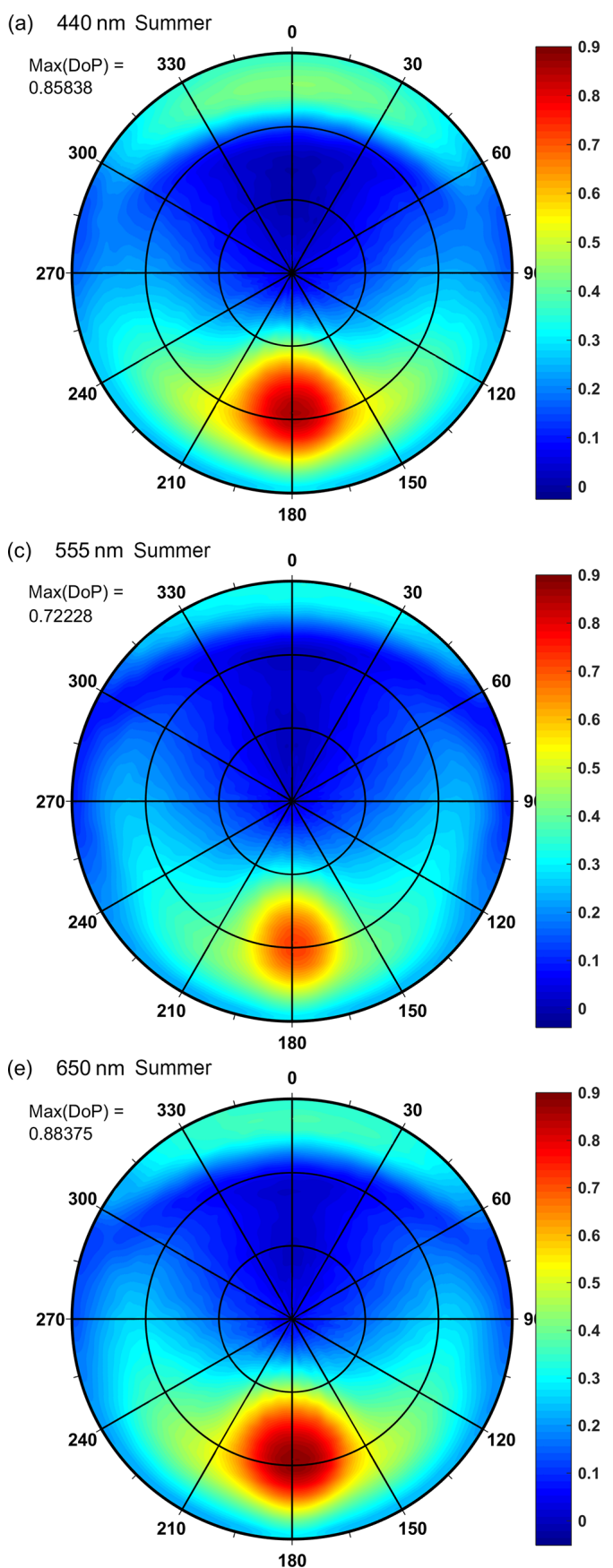

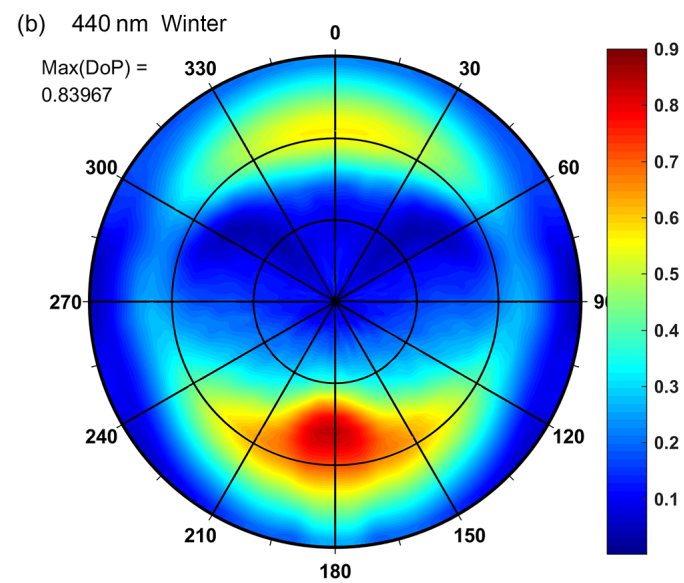

(d) $555 \mathrm{~nm}$ Winter

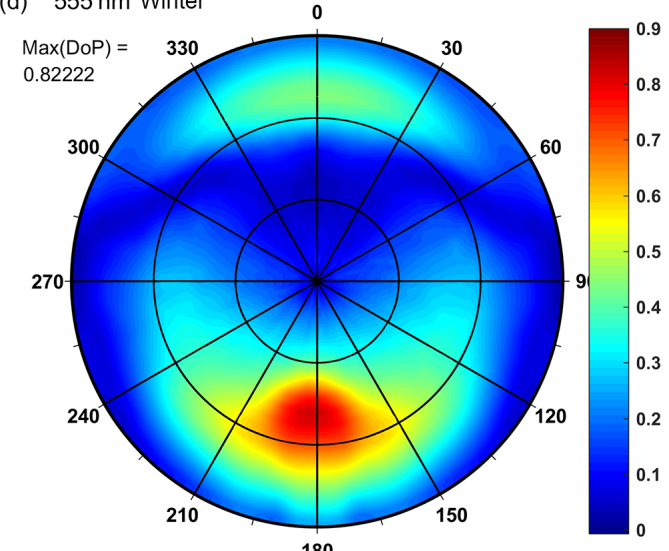

(f) $650 \mathrm{~nm}$ Winter

0

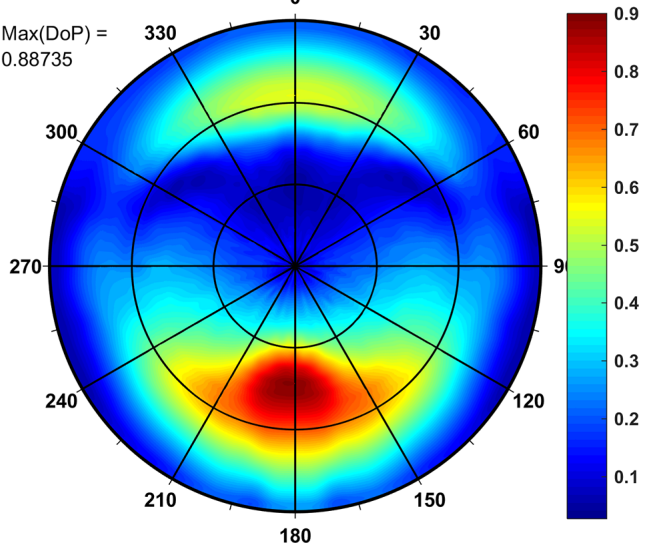

Figure 4. Simulation results of above-water upwelling radiance for average IOPs of open Baltic Sea water, for speed of wind of $5 \mathrm{~m} \mathrm{~s}^{-1}$ : (a) DoP in the summer season, $\lambda=440 \mathrm{~nm}, \mathrm{SZA} 45^{\circ}$, (b) DoP in the winter season, $\lambda=440 \mathrm{~nm}$, SZA $75^{\circ}$, (c) DoP in the summer season, $\lambda=555 \mathrm{~nm}, \mathrm{SZA} 45^{\circ}$, (d) DoP in the winter season, $\lambda=555 \mathrm{~nm}, \mathrm{SZA} 75^{\circ}$, (e) DoP in the summer season, $\lambda=650 \mathrm{~nm}, \mathrm{SZA} 45^{\circ},(\mathbf{f})$ DoP in the winter season, $\lambda=650 \mathrm{~nm}$, SZA $75^{\circ}$. Concentric circles inside mean zenith angles of 30 and $60^{\circ}$, respectively.

and gulfs are characterized by similar values of DoP in each season. For the wavelength of $440 \mathrm{~nm}$, in the summer, the differences of $\max (\mathrm{DoP})$ between the open Baltic and other regions reach 0.02-0.04, while in the winter those differences exceed 0.05 . For the $555 \mathrm{~nm}$ band, in the summer, the differences of $\max (\mathrm{DoP})$ between the open Baltic and other regions reach 0.06-0.09 and in the winter these differences reach $0.07-0.09$, respectively. We also observed another regional difference in the angular position of the maxima of DoP that is noticeable in the winter season only. Two maxima of the DoP cross-sections are closer for open Baltic waters than for gulfs and coastal waters. 
(a) Summer $5 \mathrm{~m} \mathrm{~s}^{-1}$

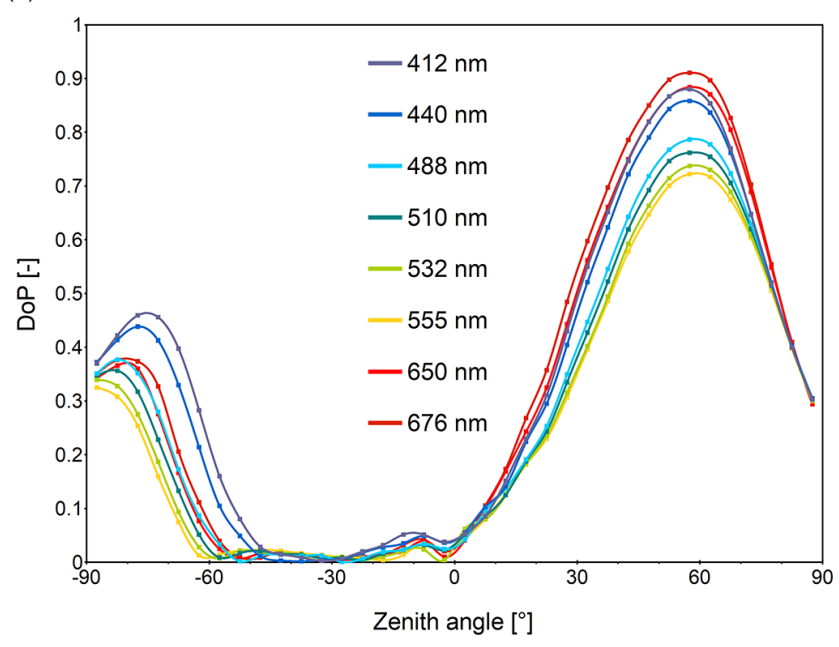

(c) Summer $15 \mathrm{~ms}^{-1}$

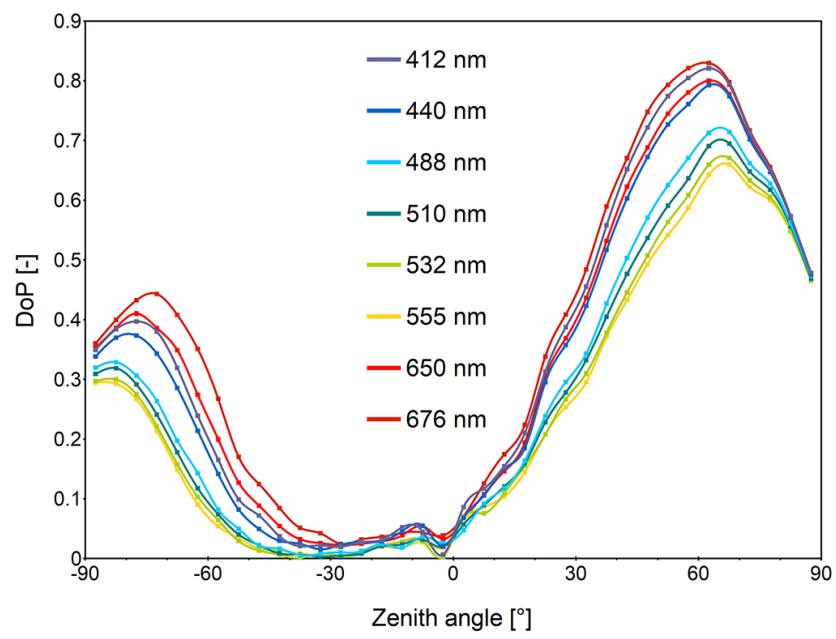

(b) Winter $5 \mathrm{~ms}^{-1}$

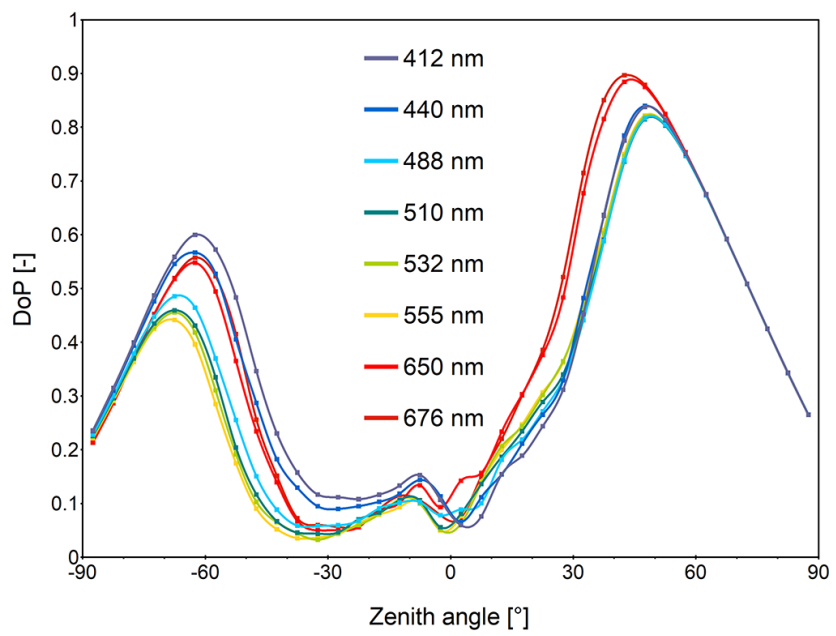

(d) Winter $15 \mathrm{~ms}^{-1}$

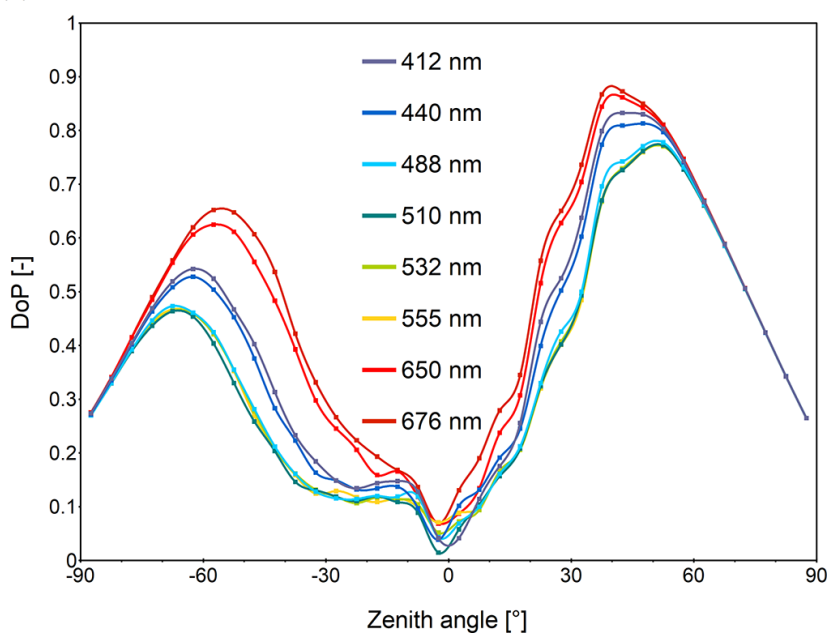

Figure 5. Degree of polarization plotted for the principal plane, e.g., plane containing both the incident ray of the Sun and zenith direction (cross-section through polar plots for azimuths 0 and $180^{\circ}$ ). Azimuth of $0^{\circ}$ is the azimuth of Sun position is marked by negative zenith angles, while azimuth $180^{\circ}$, which contains the Sun reflection, is marked by positive zenith angles. Simulation results for open Baltic Sea water: (a) summer season, SZA $45^{\circ}$, wind speed $5 \mathrm{~m} \mathrm{~s}^{-1}$, (b) winter season, SZA $75^{\circ}$, wind speed $5 \mathrm{~m} \mathrm{~s}^{-1}$, (c) summer season, $\mathrm{SZA} 45^{\circ}$, wind speed $15 \mathrm{~m} \mathrm{~s}^{-1}$, (d) winter season, SZA $75^{\circ}$, wind speed $15 \mathrm{~m} \mathrm{~s}^{-1}$

In the following section, we explain that the degree of polarization depends on the absorption-to-attenuation ratio, and all its regional changes are the result of the absorption-toattenuation ratio variability.

The results of our simulations are in qualitative agreement with the measurements of above-water DoLP of the total upwelling radiance presented by Freda et al. (2015). This agreement is the similarity of the peak of degree of polarization on the polar plots, which are stretched along the azimuth angles. Freda et al. (2015) obtained lower values of measured DoLP with a maximum of 30\%-40\% (see Figs. 1 and 2 in Freda et al., 2015), which is presumably caused by different weather conditions and unknown environmental parameters during measurements, such as a high absorption coefficient in the waters of the river mouth, different aerosol optical depth or other parameters. However, despite the differences in the maximum degree of polarization, the angular distribution patterns are similar, with the peak in the vicinity of the Sun reflection azimuth angle.

\subsection{DoP dependence on the absorption-to-attenuation ratio}

This section contains the comparison of the degree of polarization for summer and winter seasons as a function of the absorption-to-attenuation ratio.

The total $a(\lambda) / c(\lambda)$ ratio (see Table 1) is higher in the open Baltic water than in other regions because of the low scattering coefficients (Sagan, 2008). The value of the latter is determined mainly by the concentration of suspended matter, 
(a) $440 \mathrm{~nm}$

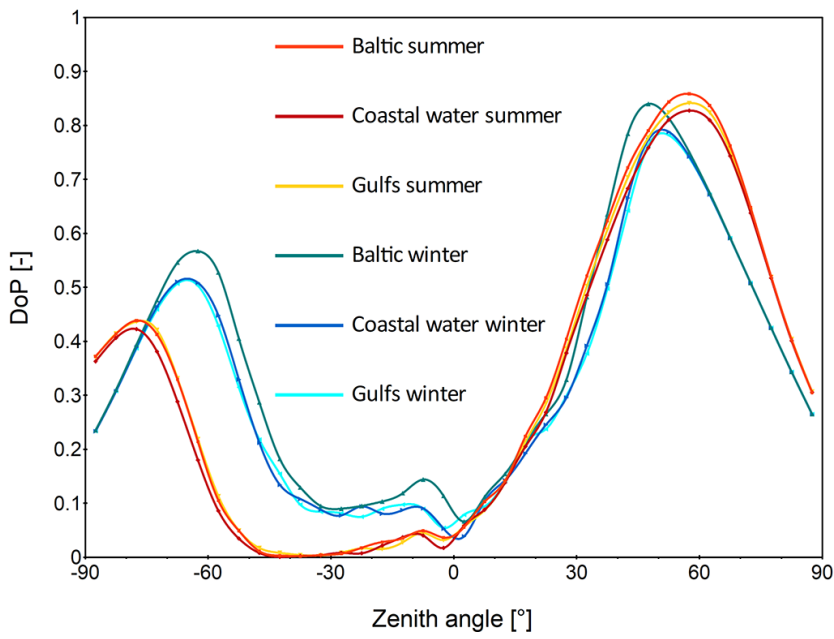

(b) $555 \mathrm{~nm}$

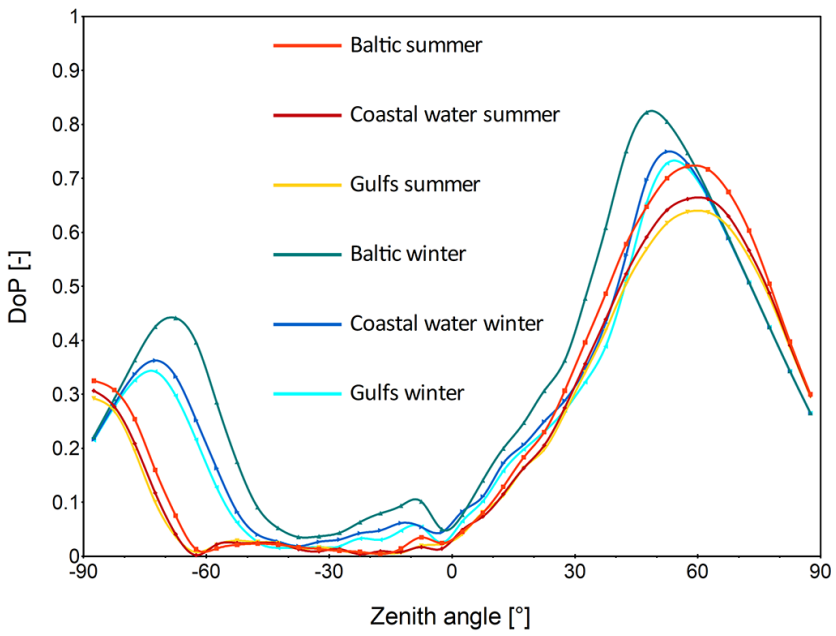

Figure 6. Degree of polarization plotted for the principal plane, i.e., plane containing both incident ray of the Sun and zenith direction (cross-section through polar plots for azimuths 0 and $180^{\circ}$ ). Azimuth of $0^{\circ}$ is marked by negative zenith angles. Simulation results are for wind speed of $5 \mathrm{~m} \mathrm{~s}^{-1}$ for all types of water and two seasons: (a) 440 and (b) $555 \mathrm{~nm}$.

which in open waters is significantly lower than in gulfs or coastal/nearshore waters. According to Sagan (2008), the average particle scattering coefficient does not depend strongly on wavelengths, and in open Baltic waters in the winter season it varies between 0.15 (for $676 \mathrm{~nm}$ ) and 0.19 (for $412 \mathrm{~nm})$. In the same season, but in the waters of gulfs, the average particle scattering coefficient varies between 0.77 (for $676 \mathrm{~nm}$ ) and 1.00 (for $412 \mathrm{~nm}$ ). For the influence of water type on DoP, regardless of the wavelength and wind speed, the lowest $\max (\mathrm{DoP})$ values in winter are observed in the waters of gulfs. These waters are characterized by the highest scattering coefficients because of the high inflow of particulate matter with river waters. However, in the summer season, the lowest peak of DoP is observed for spectral bands from 412 to $532 \mathrm{~nm}$ in coastal waters and in wavelengths from 555 to $676 \mathrm{~nm}$ in gulfs. The values of $a(\lambda) / c(\lambda)$ for these types of water differ by less than $5 \%$ except for the 650 and $676 \mathrm{~nm}$ spectral bands.

All the values of maximum DoP of above-water upwelling radiance obtained for each absorption-to-attenuation ratio are collected in Fig. 7. The summer season case is depicted in Fig. 7a, while the winter case is depicted in Fig. 7b. The water types are marked with different symbols, and two wind speeds are marked with different colors. The correlations of the $\max (\mathrm{DoP})$ to the ratio of $a(\lambda) / c(\lambda)$ are approximately linear. However, correlation coefficient analysis has shown that the power functions are better matched. The reason for the nonlinearity of this correlation may be related to the potential obtaining or even exceeding one by the value of DoP for certain combinations of absorption and attenuation coefficients. The trend line for the plot depicted in Fig. 7a shows the relationship of the maximum of DoP to the ratio of $a(\lambda) / c(\lambda)$ for the summer season and in Fig. 7b for the
Table 2. Parameters of Eq. (3), which describes the power trend lines in Fig. 4a and b.

\begin{tabular}{|c|c|c|c|}
\hline Simulation conditions & A & $\mathrm{B}$ & $R^{2}$ \\
\hline SZA $45^{\circ}$, wind speed $5 \mathrm{~m} \mathrm{~s}^{-1}$ & 1.102 & 0.262 & 0.973 \\
\hline SZA $45^{\circ}$, wind speed $15 \mathrm{~m} \mathrm{~s}^{-1}$ & 0.997 & 0.250 & 0.996 \\
\hline SZA $75^{\circ}$, wind speed $5 \mathrm{~m} \mathrm{~s}^{-1}$ & 0.903 & 0.117 & 0.906 \\
\hline SZA $75^{\circ}$, wind speed $15 \mathrm{~m} \mathrm{~s}^{-1}$ & 0.914 & 0.173 & 0.990 \\
\hline
\end{tabular}

winter season, respectively. The trend lines presented may be described by the following power functions:

$\max (\mathrm{DoP})=A\left(\frac{a(\lambda)}{c(\lambda)}\right)^{B}$,

whose parameters are collected in Table 2. These correlations are obtained for various spectral channels. Hence, they are wavelength-independent for the examined visible spectral range.

An analysis of all collected data shows that higher values of maximum DoP are observed for lower wind speed. Moreover, $\max (\mathrm{DoP})$ has a higher range of variability in the summer season than in the winter. Figure 7a (summer season) shows that values of $\max (\mathrm{DoP})$ are between 0.64 and 0.91 for the wind speed of $5 \mathrm{~m} \mathrm{~s}^{-1}$ and between 0.61 and 0.83 for the wind speed of $15 \mathrm{~m} \mathrm{~s}^{-1}$. However, in Fig. $7 \mathrm{~b}$ (winter season), the values are between 0.73 and 0.9 for the wind speed of $5 \mathrm{~m} \mathrm{~s}^{-1}$ and between 0.66 and 0.87 for the wind speed of $15 \mathrm{~m} \mathrm{~s}^{-1}$. Power trend lines for the same wind speed for summer and winter seasons (in Fig. 7a and b) intersect. For a wind speed of $5 \mathrm{~m} \mathrm{~s}^{-1}$, by $a(\lambda) / c(\lambda)$ equal to 0.26 , both power functions reach the same $\max (\mathrm{DoP})$ of 
(a)

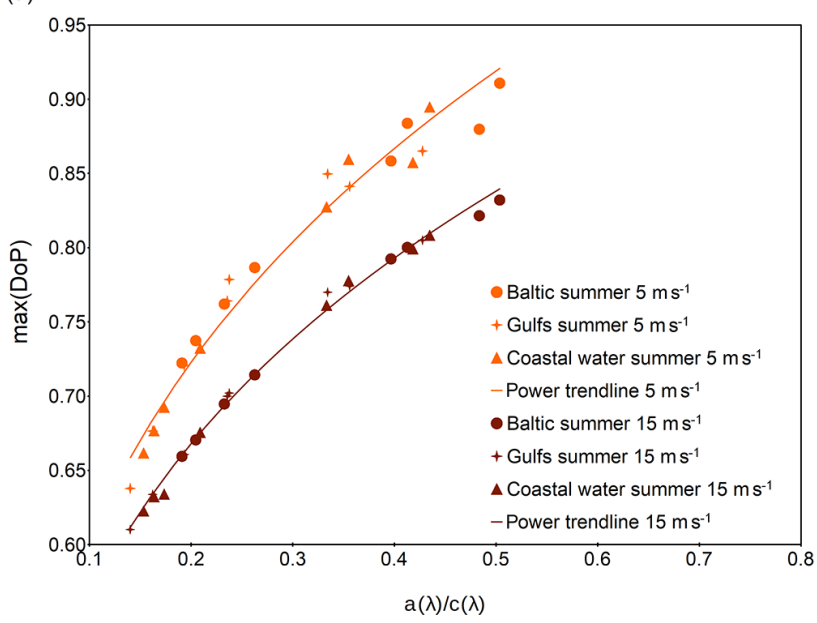

(b)

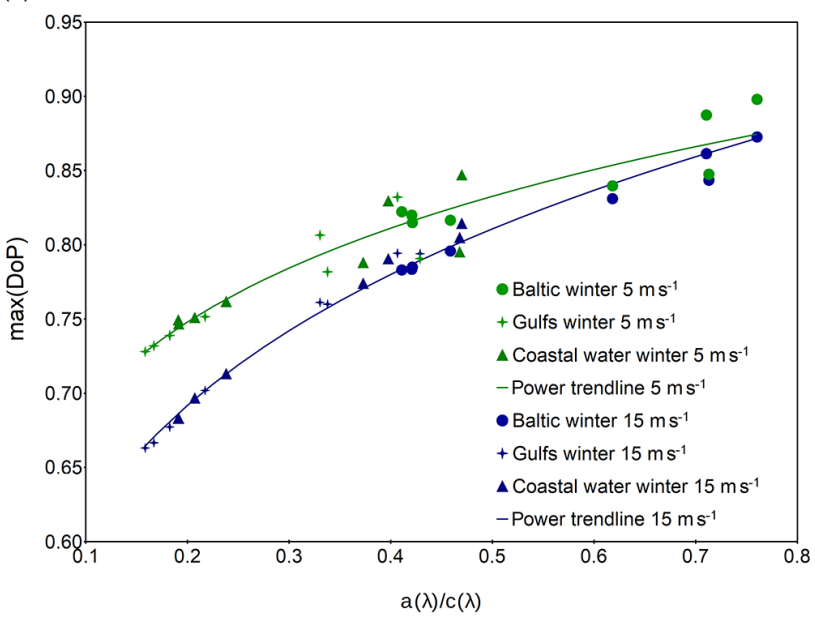

Figure 7. Values of maximum of degree of polarization against absorption-to-attenuation ratios $a(\lambda) / c(\lambda)$ for average values of IOPs presented in Table 1, plotted for (a) the summer season and (b) the winter season.

0.77. For a wind speed of $15 \mathrm{~m} \mathrm{~s}^{-1}$, by $a(\lambda) / c(\lambda)$ equal to 0.32 , both power functions reach the same value of 0.75 . For lower absorption-to-attenuation ratios, winter DoPs have higher values than summer and for higher $a(\lambda) / c(\lambda)$ values, the summer DoPs are higher.

The reason for the correlation of the maximum DoP with the absorption-to-attenuation ratio is the occurrence of multiple scattering in water depth. The degree of polarization tends to decrease after multiple scattering events. A high absorption-to-attenuation ratio means simply low scatteringto-attenuation impact and hence shallow penetration of light in the water column and low participation in multiple scattering that decreases the DoP. Such conclusion is in accordance with Piskozub and Freda (2013), who examined the influence of single scattering albedo on the polarization of waterleaving radiance. Their results show that in the Sun reflection plane, the highest value of DoP is observed when the total scattering coefficient is the lowest (see Fig. 3 in Piskozub and Freda, 2013).

The influence of wind speed on the DoP values shown in Fig. $7 \mathrm{a}$ and $\mathrm{b}$ is very clear: sea-surface roughness depolarizes the reflected light. Zhou et al. (2013) demonstrated that wind speed and wind direction can change the polarization patterns of reflected skylight from a rough sea surface to a certain extent. Our study shows, in particular, that high wind speed results in lower values of $\max (\mathrm{DoP})$ of the total upwelling radiance. Such regularity is filled for all types of water and all spectral bands.

Our algorithm does not consider possible additional depolarization, which is likely especially for high wind speeds $\left(15 \mathrm{~m} \mathrm{~s}^{-1}\right)$. This can be caused by whitecaps (Hu et al., 2008), air bubble entrainment and possibly more sea spray generation. Moreover, additional factors that may decrease the DoP value for high SZA (winter season) are wave- shadowing effects of incident and multiple reflected rays (see Hieronymi, 2016), which are not considered in this paper.

The results of the correlation of the maximum DoP with the absorption-to-attenuation ratio seem to be coincident with the results of Ibrahim et al. (2012), who studied the degree of linear polarization just below the air-water interface. Their correlation of attenuation-to-absorption ratio with DoLP displays a hyperbolic shape (see Figs. 5 to 8 in Ibrahim et al., 2012). Therefore, for an inverted absorptionto-attenuation ratio, it would be near linear. The modeling results of Ibrahim et al. cannot be compared directly to the results presented in this paper because they received DoLP just below the sea surface, and we focused on DoP just above the surface. However, our choice of seawater absorption-toattenuation ratio, which can be called the relative absorption value (to total attenuation), as a parameter correlated to degree of polarization seems to be more suitable.

\section{Conclusions}

In this paper, we have investigated the relationship between the seawater absorption-to-attenuation ratio and the degree of radiance polarization above the rough sea surface. Using a Monte Carlo polarized radiative transfer model, we compared simulated polarization patterns in three optically different regions in the southern Baltic (i.e., open Baltic, gulfs, coastal waters), two seasons (defined by their typical solar zenith angles: $45^{\circ}$ for summer and $75^{\circ}$ for winter) and two wind speeds of 5 and $15 \mathrm{~m} \mathrm{~s}^{-1}$, each for nine visible spectral bands (412, 440, 488, 510, 532, 555, 650, 676, $715 \mathrm{~nm})$. The use of the modeling tool allowed us to exclude unwanted and unpredictable variables (such as weather conditions and aerosol optical thickness) and to conduct undisturbed com- 
parison of the DoPs of combined water-leaving and reflected components of upwelling radiance.

We found that the variability of the maximum of DoP depends more on seasonal than regional changes and can be explained to a large degree by the absorption-to-attenuation ratio. A thorough analysis has shown that there is a strong correlation between $\max (\mathrm{DoP})$ and the ratio mentioned previously. The correlation is well described $\left(R^{2}>0.90\right)$ by a power function with factor A close to 1 and factor B depending more on SZA than on the wind speed. In our study, seasonal variability of the degree of polarization is higher/more significant than regional variability. However, this may be true only in the southern Baltic region due to the characteristically different SZA ranges in the winter and summer seasons.

For the ocean color remote sensing application, only the water-leaving part of the upwelling radiance carries useful information about bio-optical parameters of seawater, although it is a small fraction of the total upwelling radiance. Polarized radiative transfer modeling makes it possible to separate the water-leaving part and, in this case, the noise-inducing reflected part and therefore to enhance the quality of information on the seawater optically active components retrieved by above-water sensors - airborne or satellites. Our study is a step toward inclusion of polarization properties in the biooptical models in the Baltic Sea. However, the conclusions from the research, in our opinion, should be universal and apply also to other water bodies.

Data availability. All data and modeling results are available online at the following repository: http://kepler.umg.edu.pl/ wfreda/ AtoCinDoP/start.html (Freda, 2009).

Author contributions. SS provided the results of absorption and attenuation coefficient measurements, and a contribution to the article on IOPs. KH took part in the preparation of the manuscript and data analysis. WF performed the modeling, developed its results and wrote a large part of the manuscript.

Competing interests. The authors declare that they have no conflict of interest.

Acknowledgements. The authors are grateful to Jacek Piskozub for his valuable comments and suggestions.

Financial support. This research has been supported by the National Science Centre Poland (grant no. UMO2012/07/D/ST10/02865) and by Gdynia Maritime University (grant no. WM/2019/PZ/05).
Review statement. This paper was edited by Oliver Zielinski and reviewed by two anonymous referees.

\section{References}

Benassai, G., Montuori, A., Migliaccio, M., and Nunziata, F.: Sea wave modeling with X-band COSMO-SkyMed ${ }^{\circledR}$ SAR-derived wind field forcing and applications in coastal vulnerability assessment, Ocean Sci., 9, 325-341, https://doi.org/10.5194/os-9325-2013, 2013.

Berthon, J. F., Shybanov, E., Lee, M., and Zibordi, G.: Measurements and modeling of the volume scattering function in the coastal northern Adriatic Sea, Appl. Opt., 46, 5189-5203, https://doi.org/10.1364/AO.46.005189, 2007.

Bricaud, A., Claustre, H., Ras, J., and Oubelkheir K.: Natural variability of phytoplanktonic absorption in oceanic waters: Influence of the size structure of algal populations, J. Geophys. Res., 109, C11010, https://doi.org/10.1029/2004JC002419, 2004.

Chami, M.: Importance of the polarization in the retrieval of oceanic constituents from the remote sensing reflectance, J. Geophys. Res., 112, C05026, https://doi.org/10.1029/2006JC003843, 2007.

Chami, M., Shybanov, E. B., Churilova, T. Y., Khomenko, G. A., Lee, M. E.-G., Martynov, O. V., Berseneva, G. A., and Korotaev, G. K.: Optical properties of the particles in the Crimea coastal waters (Black Sea), J. Geophys. Res., 110, C11020, https://doi.org/10.1029/2005JC003008, 2005.

Chami, M., Lafrance, B., Fougnie, B., Chowdhary, J., Harmel, T., and Waquet, F.: OSOAA: a vector radiative transfer model of coupled atmosphere-ocean system for a rough sea surface application to the estimates of the directional variations of the water leaving reflectance to better process multi-angular satellite sensors data over the ocean, Opt. Express, 23, 27829-27852, https://doi.org/10.1364/OE.23.027829, 2015.

Chowdhary, J., Cairns, B., and Travis, L. D.: Case studies of aerosol retrievals over the ocean from multiangle, multispectral photopolarimetric remote sensing data, J. Atmos. Sci., 59, 383-397, 2002.

Cox, C. and Munk, W.: Slopes of the Sea Surface Deduced from Photographs of Sun Glitter; Bulletin of the Scripps Institution of Oceanography of the University of California, La Jolla, University of California Press, Oakland, CA, USA, 1956.

Cronin, T. W. and Marshall, J.: Patterns and properties of polarized light in air and water, Philos. T. R. Soc. B, 366, 619-626, https://doi.org/10.1098/rstb.2010.0201, 2011.

Cunningham, A., Wood, P., and McKee D.: Brewster-angle measurements of sea-surface reflectance using a high resolution spectroradiometer, J. Opt. A, 4, S29-S33, https://doi.org/10.1088/1464-4258/4/4/361, 2002.

D'Alimonte, D. and Kajiyama, T.: Effects of light polarization and waves slope statistics on the reflectance factor of the sea surface, Opt. Express, 24, 7922-7942, https://doi.org/10.1364/OE.24.007922, 2016

Drozdowska, V., Wróbel, I., Markuszewski, P., Makuch, P., Raczkowska, A., and Kowalczuk, P.: Study on organic matter fractions in the surface microlayer in the Baltic Sea by spectrophotometric and spectrofluorometric methods, Ocean Sci., 13, 633-647, https://doi.org/10.5194/os-13-633-2017, 2017. 
Foster, R. and Gilerson, A.: Polarized Transfer Functions of the Ocean Surface for Above-Surface Determination of the Vector Submarine Light Field, Appl. Optics, 55, 9476-9494, https://doi.org/10.1364/AO.55.009476, 2016.

Freda, W.: Spectral dependence of the correlation between the backscattering coefficient and the volume scattering function measured in the Southern Baltic Sea, Oceanologia, 54, 355-367, https://doi.org/10.5697/oc.54-3.355, 2012.

Freda, W.: Results of Monte Carlo model for seawater absortionto-attenuation ratio impact on DoP, Gdynia Maritime University, available at: http://kepler.umg.edu.pl/ wfreda/AtoCinDoP/start. html, last access: 30 May 2019.

Freda, W.: Comparison of the spectral-angular properties of light scattered in the Baltic Sea and oil emulsions, J. Eur. Opt. Soc.Rapid, 9, 14017, https://doi.org/10.2971/jeos.2014.14017, 2014.

Freda, W. and Piskozub, J.: Improved method of Fournier-Forand marine phase function parameterization, Opt. Express, 15, 12763-12768, https://doi.org/10.1364/OE.15.012763, 2007.

Freda, W., Król, T., Martynov, O. V., Shybanov, E. B., and Hapter, R.: Measurements of scattering function of sea water in southern Baltic, Eur. Phys. J.-Spec. Top., 144, 147-154, https://doi.org/10.1140/epjst/e2007-00119-6, 2007.

Freda, W., Piskozub, J., and Toczek H.: Polarization imaging over sea surface - a method for measurements of Stokes components angular distribution, J. Eur. Opt. Soc.-Rapid, 10, 15060, https://doi.org/10.2971/jeos.2015.15060, 2015.

Frouin, R., Pouliquen, E., and Breon, F.-M.: Ocean color remote sensing using polarization properties of reflected sunlight, in: CNES, Proceedings of 6th International Symposium on Physical Measurements and Signatures in Remote Sensing, Val D'Isere, France, 17-22 January 1994, 665-674, 1994.

Gilerson, A., Zhou, J., Oo, M., Chowdhary, J., Gross, B. M., Moshary, F., and Ahmedet, S.: Retrieval of chlorophyll fluorescences from reflectance spectra through polarization discrimination: modeling and experiments, Appl. Optics, 45, 5568-5581, https://doi.org/10.1364/AO.45.005568, 2006.

Hajnsek, I., Pottier, E., and Cloude, S. R.: Inversion of surface parameters from polarimetric SAR, IEEE T. Geosci. Remote Sens., 41, 727-744, https://doi.org/10.1109/TGRS.2003.810702, 2003.

Harmel, T. and Chami, M.: Influence of Polarimetric Satellite Data Measured in the Visible Region on Aerosol Detection and on the Performance of Atmospheric Correction Procedure over Open Ocean Waters, Opt. Express, 19, 20960-20983, https://doi.org/10.1364/OE.19.020960, 2008.

Harmel, T. and Chami, M.: Estimation of the sunglint radiance field from optical satellite imagery over open ocean: Multidirectional approach and polarization aspects, J. Geophys. Rese.-Ocean., 118, 76-90, https://doi.org/10.1029/2012JC008221, 2013.

Harmel, T., Tonizzo, A., Ibrahim, A., Gilerson, A., Chowdhary, J., and Ahmed S.: Measuring underwater polarization field from above-water hyperspectral instrumentation for water composition retrieval, in: Proc. SPIE 8175, Remote Sensing of the Ocean, Sea Ice, Coastal Waters, and Large Water Regions, 7817509 , https://doi.org/10.1117/12.898261, 2011.

Harmel, T., Gilerson, A., Tonizzo, A., Chowdhary, J., Weidemann, A., Arnone, R., and Ahmed, S.: Polarization impacts on the water-leaving radiance retrieval from abovewater radiometric measurements, Appl. Optics, 51, 8324-8340, https://doi.org/10.1364/AO.51.008324, 2012.
Hasekamp, O. P., and Landgraf, J.: Retrieval of aerosol properties over the ocean from multispectral single-viewing-angle measurements of intensity and polarization: Retrieval approach, information content, and sensitivity study, J. Geophys. Res., 110, https://doi.org/10.1029/2005JD006212, 2005.

Haule, K. and Freda W.: The effect of dispersed Petrobaltic oil droplet size on photosynthetically active radiation in marine environment, Environ. Sci. Pollut. R., 23, 6506-6516, https://doi.org/10.1007/s11356-015-5886-4, 2016.

Haule, K., Freda, W., Darecki, M., and Toczek, H.: Possibilities of optical remote sensing of dispersed oil in coastal waters, Estuar. Coast. Shelf Sci., 195, 76-87, https://doi.org/10.1016/j.ecss.2016.07.013, 2017.

He, X., Pan, D., Bai, Y., Wang, D., and Hao, Z.: A new simple concept for ocean colour remote sensing using parallel polarisation radiance, Sci. Rep., 4, 3748, https://doi.org/10.1038/srep03748, 2014.

Hieronymi, M.: Polarized reflectance and transmittance distribution functions of the ocean surface, Opt. Express, 24, A1045-A1068, https://doi.org/10.1364/OE.24.0A1045, 2016.

Hu, Y., Stamnes, K., Vaughan, M., Pelon, J., Weimer, C., Wu, D., Cisewski, M., Sun, W., Yang, P., Lin, B., Omar, A., Flittner, D., Hostetler, C., Trepte, C., Winker, D., Gibson, G., and Santa-Maria, M.: Sea surface wind speed estimation from spacebased lidar measurements, Atmos. Chem. Phys., 8, 3593-3601, https://doi.org/10.5194/acp-8-3593-2008, 2008.

Ibrahim, A., Gilerson, A., Harmel, T., Tonizzo, A., Chowdhary, J., and Ahmed, S.: The relationship between upwelling underwater polarization and attenuation/absorption ratio, Opt. Express, 23, 25662-25680, https://doi.org/10.1364/OE.20.025662, 2012.

Ibrahim, A., Gilerson, A., Chowdhary, J., and Ahmed, S.: Retrieval of macro- and micro-physical properties of oceanic hydrosols from polarimetric observations, Remote Sens. Environ., 186, 548-566, https://doi.org/10.1016/j.rse.2016.09.004, 2016.

Ivanoff, A. and Waterman, T. H.: Factors, mainly depth and wavelength, affecting underwater polarized light, J. Mar. Res., 16, 283-307, 1958.

Kattawar, G. W., Plass, G. N., and Guinn, J. A.: Monte Carlo Calculations of the Polarization of Radiation in the Earth's Atmosphere-Ocean System, J. Phys. Oceanogr., 3, 353-372, 1973.

Kokhanovsky, A. A., Budak, V. P., Cornet, C., Duan, M., Emde, C., Katsev, I. L., Klyukov, D. A., Korkin S. V., C-Labonnote, L., Mayer, B., Ming, Q., Nakajima, T., Ota Y., Prikhach, A. S., Rozanov, V. V., Yokota, T., and Zege, E. P.: Benchmark results in vector atmospheric radiative transfer, J. Quant. Spectros. Ra., 111, 1931-1946, https://doi.org/10.1016/j.jqsrt.2010.03.005, 2010.

Korkin, S., Lyapustin, A., Sinyuk, A., Holben, B., and Kokhanovsky, A.: Vector radiative transfer code SORD: Performance analysis and quick start guide, J. Quant. Spectrosc. Ra., 200, 295-310, https://doi.org/10.1016/j.jqsrt.2017.04.035, 2017

Kowalczuk, P.: Seasonal variability of yellow substances absorption in the surface layer of the Baltic Sea, J. Geophys. Res., 104, 30047-30058, https://doi.org/10.1029/1999JC900198, 1999.

Kowalczuk, P. and Kaczmarek, S.: Analysis of temporal and spatial variability of "yellow substance" absorption in the Southern Baltic, Oceanologia, 38, 3-32, 1996. 
Kowalczuk, P., Olszewski, J., Darecki, M., and Kaczmarek, S.: Empirical relationships between coloured dissolved organic matter (CDOM) absorption and apparent optical properties in Baltic Sea waters, Int. J. Remote Sens., 26, 345-370, https://doi.org/10.1080/01431160410001720270, 2005.

Kowalczuk, P., Stedmon, C. A., and Markager, S.: Modeling absorption by CDOM In the Baltic Sea from season, salinity and chlorophyll, Mar. Chem., 101, 1-11, https://doi.org/10.1016/j.marchem.2005.12.005, 2006.

Kowalczuk, P., Darecki, M., Zabłocka, M., and Górecka, I.: Validation of empirical and semi-analytical remote sensing algorithms for estimating absorption by Coloured Dissolved Organic Matter in the Baltic Sea from SeaWiFS and MODIS imagery, Oceanologia, 52, 171-196, https://doi.org/10.5697/oc.52-2.171, 2010.

Lee, M. E. and Lewis, M. R.: A new method for the measurement of the optical volume scattering function in the upper ocean, J. Atmos. Ocean. Technol., 20, 563-571, 2003.

Liu, J., He, X., Liu, J., Bai, Y., Wang, D., Chen, T., Wang, Y., and Zhu, F.: Polarization-based enhancement of ocean color signal for estimating suspended particulate matter: radiative transfer simulations and laboratory measurements, Opt. Express, 25, A323-A337, https://doi.org/10.1364/OE.25.00A323, 2017.

Loisel, H., Duforet, L., Dessailly, D., Chami, M., and Dubuisson, P.: Investigation of the Variations in the Water Leaving Polarized Reflectance from the POLDER Satellite Data over two Biogeochemical Contrasted Oceanic Areas, Opt. Express, 16, 1290512918, https://doi.org/10.1364/OE.16.012905, 2008.

McKee, D., Piskozub, J., and Brown, I.: Scattering error corrections for in situ absorption and attenuation measurements, Opt. Express, 16, 19480-19492, https://doi.org/10.1364/OE.16.019480, 2008.

McKee, D., Piskozub J., Rottgers, R., and Reynolds, R. A.: Evaluation and Improvement of an Iterative Scattering Correction Scheme for in situ Absorption and Attenuation Measurements, J. Atmos. Ocean. Technol., 30, 1527-1541, https://doi.org/10.1175/JTECH-D-12-00150.1, 2013.

Meler, J., Kowalczuk, P., Ostrowska, M., Ficek, D., Zabłocka, M., and Zdun, A.: Parameterization of the light absorption properties of chromophoric dissolved organic matter in the Baltic Sea and Pomeranian lakes, Ocean Sci., 12, 1013-1032, https://doi.org/10.5194/os-12-1013-2016, 2016a.

Meler, J., Ostrowska, M., and Stoń-Egiert, J.: Seasonal and spatial variability of phytoplankton and non-algal absorption in the surface layer of the Baltic, Estuar. Coast. Shelf Sci., 180, 123-135, https://doi.org/10.1016/j.ecss.2016.06.012, 2016b.

Mishchenko, M. I. and Travis, L. D.: Satellite retrieval of aerosol properties over the ocean using polarization as well as intensity of reflected sunlight, J. Geophys. Res., 102, 16989-17013, https://doi.org/10.1029/96JD02425, 1997.

Mobley, C. D.: Polarized Reflectance and Transmittance Properties of Wind-blown Sea Surfaces, Appl. Optics, 54, 4828-4849, https://doi.org/10.1364/AO.54.004828, 2015.

Olszewski, J., Sagan S., and Darecki M.: Spatial and temporal changes in some optical parameters in the southern Baltic, Oceanologia, 33, 87-103, 1992.

Ota, Y., Higurashi, A., Nakajima, T., and Yokota, T.: Matrix formulations of radiative transfer including the polarization effect in a coupled atmosphere-ocean system, J. Quant. Spectrosc. Ra., 111, 878-894, https://doi.org/10.1016/j.jqsrt.2009.11.021, 2010.
Otremba, Z.: Oil droplets as light absorbents in seawater, Opt. Express, 15, 8592-8597, https://doi.org/10.1364/OE.15.008592, 2007.

Otremba, Z.: Oil Droplet clouds suspended in the sea: can they be remotely detected?, Remote Sens., 8, 857, https://doi.org/10.3390/rs8100857, 2016.

Otremba, Z., Zielinski, O., and Hu, C.: Optical contrast of oil dispersed in seawater under windy conditions, J. Eur. Opt. Soc.Rapid, 8, 13051, https://doi.org/10.2971/jeos.2013.13051, 2013.

Piskozub, J. and Freda, W.: Signal of single scattering albedo in water leaving polarization, J. Eur. Opt. Soc.-Rapid, 8, 13055, https://doi.org/10.2971/jeos.2013.13055, 2013.

Piskozub, J., Flatau, P. J., and Zaneveld, J. R. V.: Monte Carlo study of the scattering error of a quartz reflective absorption tube, $\mathrm{J}$. Ocean. Atmos. Technol., 18, 438-445, 2001.

Piskozub, J. and McKee, D.: Effective scattering phase functions for the multiple scattering regime, Opt. Express, 19, 4786-4794, https://doi.org/10.1364/OE.19.004786, 2011.

Pope, R. M. and Fry, E. S.: Absorption spectrum (380-700 nm) of pure water, II Integrating cavity measurements, Appl. Optics, 36, 8710-8723, https://doi.org/10.1364/AO.36.008710, 1997.

Pust, N. J., Dahlberg, A. R., Thomas, M. J., and Shaw, J. A.: Comparison of full-sky polarization and radiance observations to radiative transfer simulations which employ AERONET products, Opt. Express, 19, 18602-18613, https://doi.org/10.1364/OE.19.018602, 2011.

Rudź, K., Darecki, M., and Toczek, H.: Modelling the influence of oil content on optical properties of seawater in the Baltic Sea, J. Eur. Opt. Soc.-Rapid, 8, 13063, https://doi.org/10.2971/jeos.2013.13063, 2013.

Sagan, S.: The inherent water optical properties of Baltic waters, Diss. Monogr., 21, IOPAS Sopot, Poland, 244 pp., 2008 (in Polish).

Sammartino, M., Di Cicco, A., Marullo, S., and Santoleri, R.: Spatio-temporal variability of micro-, nano- and pico-phytoplankton in the Mediterranean Sea from satellite ocean colour data of SeaWiFS, Ocean Sci., 11, 759-778, https://doi.org/10.5194/os-11-759-2015, 2015.

Schulz, F. M., Stamnes, K., and Weng, F.: VDISORT: An improved and generalized discrete ordinate method for polarized (vector) radiative transfer, J. Quant. Spectrosc. Ra., 61, 105-122, https://doi.org/10.1016/S0022-4073(97)00215-X, 1999.

Shaw, J. A. and Vollmer, M.: Blue sun glints on water viewed through a polarizer, Appl. Optics, 56, G36-G41, https://doi.org/10.1364/AO.56.000G36, 2017.

Siegel, D. A., Wang, M., Maritorena, S., and Robinson, W.: Atmospheric correction of satellite ocean color imagery: the black pixel assumption, Appl. Optics, 39, 3582-3591, https://doi.org/10.1364/AO.39.003582, 2000.

Smith, R. and Baker, K.: Optical properties of the clearest natural waters $(200-800 \mathrm{~nm})$, Appl. Optics, 20, 177-184, https://doi.org/10.1364/AO.20.000177, 1981.

Soloviev, A., Maingot, C., Matt, S., Dodge, R. E., Lehner, S., Velotto, D., Brusch, S., Perrie, W., and Hochberg, E.: Fine-scale features on the sea surface in SAR satellite imagery - Part 1: Simultaneous in-situ measurements, Ocean Sci. Discuss., 9, 2885 2914, https://doi.org/10.5194/osd-9-2885-2012, 2012.

Stramski, D. and Piskozub, J.: Estimation of scattering error in spectrophotometric measurements of light absorption by aquatic par- 
ticles from 3-D radiative transfer simulations, Appl. Optics, 42, 3634-3646, https://doi.org/10.1364/AO.42.003634, 2003.

Tonizzo, A., Zhou, J., Gilerson, A., Twardowski, M. S., Gray, D. J., Arnone, R. A., Gross, B. M., Moshary, F., and Ahmed, S. A.: Polarized light in coastal waters: hyperspectral and multiangular analysis, Opt. Express, 17, 5666-5683, https://doi.org/10.1364/OE.17.005666, 2009.

Tonizzo, A., Gilerson, A., Harmel, T., Ibrahim, A., Chowdhary, J., Gross, B., Moshary, F., and Ahmed S.: Estimating particle composition and size distribution from polarized water-leaving radiance, Appl. Optics, 50, 5047-5058, https://doi.org/10.1364/AO.50.005047, 2011.

Volpe, G., Colella, S., Forneris, V., Tronconi, C., and Santoleri, R.: The Mediterranean Ocean Colour Observing System - system development and product validation, Ocean Sci., 8, 869-883, https://doi.org/10.5194/os-8-869-2012, 2012.

Volten, H., Muñoz, O., Rol, E., de Haan, J. F., Vassen, W., Hovenier, J., Muinonen, K., and Nousiainen, T.: Scattering matrices of mineral aerosol particles at $441.6 \mathrm{~nm}$ and $632.8 \mathrm{~nm}$, J. Geophys. Res., 106, 17375-17401, https://doi.org/10.1029/2001JD900068, 2001.

Voss, K. J. and Fry, E. S.: Measurement of the Mueller matrix for ocean water, Appl. Optics, 23, 4427-4439, https://doi.org/10.1364/AO.23.004427, 1984.

Wang, M.: Remote sensing of the ocean contributions from ultraviolet to near-infrared using the shortwave infrared bands: simulations, Appl. Optics, 46, 1535-1547, https://doi.org/10.1364/AO.46.001535, 2007.
Wood, P. and Cunningham, A.: Ship-borne measurements of ocean colour: Development of a CCD-based reflectance radiometer and trials on a longitudinal transect of the Atlantic Ocean, Int. J. Remote Sens., 22, 99-111, https://doi.org/10.1080/014311601750038875, 2001.

Woźniak, S. B., Meler, J., Lednicka, B., Zdun, A., and StońEgiert, J.: Inherent optical properties of suspended particulate matter in the southern Baltic Sea, Oceanologia, 53, 691-729, https://doi.org/10.5697/oc.53-3.691, 2011.

Zaneveld, J. R. V., Kitchen, J. C., and Moore, C.: The scattering error correction of reflecting tube absorption meters, Proc. SPIE, 2258, 44-55, https://doi.org/10.1117/12.190095, 1994.

Zhai, P., Knobelspiesse, K., Ibrahim, A., Franz, B., Hu, Y., Gao, M., and Frouin, R.: Water-leaving contribution to polarized radiation field over ocean, Opt. Express, 25, A689-A708, https://doi.org/10.1364/OE.25.00A689, 2017.

Zhou, G., Xu, W., Niu, C., and Zhao, H.: The polarization patterns of skylight reflected off wave water surface, Opt. Express, 21, 32549-32565, https://doi.org/10.1364/OE.21.032549, 2013.

Zhou, G., Xu, W., Niu, C., Zhang, K., Ma, Z., Wang, J., and Zhang,Y.: Versatile time-dependent spatial distribution model of sun glint for satellite-based ocean imaging, J. Appl. Rem. Sens., 11, 016020, https://doi.org/10.1117/1.JRS.11.016020, 2017.

Zibordi, G., Mélin, F., Berthon, J.-F., and Canuti, E.: Assessment of MERIS ocean color data products for European seas, Ocean Sci., 9, 521-533, https://doi.org/10.5194/os-9-521-2013, 2013. 